\title{
3 Research Square

\section{$\beta$ Arrestin inhibition induces autophagy, apoptosis, G0/G1 cell cycle arrest in agonist activated V2R receptor in breast cancer cells}

Mohamed Hessien ( $\square$ mohamed.hessien@fulbrightmail.org )

Tanta University Faculty of Science https://orcid.org/0000-0002-3782-1633

Thoria Donia

Tanta University Faculty of Science

Mohamed Kelany

Ain Shams University Faculty of Medicine

Mohamed Abouda

Tanta University Faculty of Science

\section{Research Article}

Keywords: Autophagy, apoptosis, $\beta$-Arrestin, breast cancer, Barbadin, Wortamannin

Posted Date: February 15th, 2021

DOI: https://doi.org/10.21203/rs.3.rs-187590/v1

License: (9) This work is licensed under a Creative Commons Attribution 4.0 International License.

Read Full License

Version of Record: A version of this preprint was published at Medical Oncology on March 15th, 2021.

See the published version at https://doi.org/10.1007/s12032-021-01484-z. 


\section{Abstract}

Non-visual arrestins ( $\beta$-arrestins) are endocytic proteins that mediate agonist activated GPCRs internalization and signaling pathways in an independent manner. The involvement of $\beta$-arrestins in cancer invasion and metastasis is increasingly reported. So, it is hypothesized that inhibition of $\beta$-arrstins may diminish the survival chances of cancer cells. This study aimed to evaluate the in vitro impact of inhibiting $\beta$-arrestins on the autophagic and/or apoptotic responsiveness of breast cancer cells.

We used Barbadin to selectively inhibit $\beta$-Arr/AP2 interaction in AVP stimulated V2R receptor of triple negative breast cancer cells (MDA MB-231). Autophagy was assessed by the microtubule-associated protein 1 light chain 3-II (LC3II), apoptosis was measured by Annexin-V/PI staining and cell cycle distribution was investigated based upon the DNA content using flow cytometry. Barbadin reduced cell viability to $69.1 \%$ and increased the autophagy marker LC3 II and its autophagic effect disappeared in cells transiently starved in Earle's balanced salt solution (EBSS). Also, Barbadin mildly enhanced the expression of P62 mRNA and arrested $63.7 \%$ of cells in G0/G1 phase. In parallel, the drug induced apoptosis in $29.9 \%$ of cells (by AV/PI) and $27.8 \%$ of cells were trapped in sub-G1 phase. The apoptotic effect of Barbadin was enhanced when autophagy was inhibited by the PI3K inhibitor (Wortmannin).

Conclusively, the data demonstrate the dual autophagic and apoptotic effects of $\beta$ - $\beta$ Arr/AP2 inhibition in triple negative breast cancer cells. These observations nominate $\beta$-Arrs as selective targets in breast cancer treatment.

\section{Introduction}

Autophagy is regarded as protective mechanism when cells experience unfavorable conditions. This paradigm may be altered to cytotoxic event, where excessive autophagy is implicated in autophagic (Type II) cell death [1]. Diminishing the survival chances of cancer cells may require inhibiting the autophagy mediated cytoprotective to enhance their responsiveness to chemotherapy, thereby promoting cell death either alone or in association with apoptosis [2]. The autophagy/apoptosis relation is complex and involves several intermediary molecules and signaling pathways. Both mechanisms may act independently, in parallel, or may influence one another [3]. Arrestins are a family of intracellular proteins that include visual arrestins (Arr1 and Arr4) and non-visual arrestins ( $\beta$-Arr1 $\beta$-Arr2) [4]. Both $\beta$-Arr1\&2 are widely expressed in most mammalian cell types, known with their regulatory role in GPCRs desensitization [5], and subsequent receptor-mediated signal termination. Liganded GPCRs are internalized through a mechanism involving arrestin-dependent binding to clathrin-coated pits [6]. Subsequent studies have introduced $\beta$-Arrs as a part of the multi-protein complex (receptorsome) involved in targeting receptor kinase complex to clathrin-coated pits and receptor internalization [7]. Moreover, $\beta$-Arrs mediate other pathways distinct from the $G$ protein-dependent activation. These pathways are extremely diverse, derive variable cellular responses through different GPCRs, or independent of $\mathrm{G}$ protein activation [8]. These events determine life-or-death decisions in the cell. The role of $\beta$-Arrs in cancer invasion and metastasis is reported through various signaling pathways including 
mitogen-activated protein kinase/extracellular signal regulated kinase (MAPK/ERK), Wnt/ $\beta$-catenin, and phosphoinositide-3 kinase (PI3K)/Akt [9]. Other reports have proposed the direct implication of $\beta$-Arrs in diverse types of cancer phenotypes and their participation in different stages of oncogenesis including initiation, promotion and progression [10]. Breast cancer is the leading cause of cancer related mortality among females, where the triple negative breast cancer (TNBC) constitutes about $20 \%$ of cases worldwide [11]. There are accumulating evidences indicating the implication of $\beta$-Arr in breast cancer phenotype and metastasis. In triple negative breast cancer cells (MDA MB-231), $\beta$-Arrs contributed in PAR2 mediated migration via ERK1/2 MAP kinase activation [12] and involved in cellular proliferation and migration via AMPK activation [13]. Also, they contributed in GPR161-mediated proliferation and cell migration via IQGAP1 dependent mechanism [14] and associated with resistance through regulating the expression of multidrug resistance gene (MDR1) [15]. These findings and others have nominated $\beta$-Arrs

as a potential therapeutic target against breast cancer and other cancers. The consequences of blocking the interaction between $\beta$-Arrs and the adaptor protein (AP2) of clathrin are not adequately investigated. Thus, this work was designed to explore the autophagic and apoptosis effects of the inhibition of $\beta$ Arr/AP2 interaction in hormonally stimulated breast cancer cells.

\section{Materials And Methods}

\section{Key Reagents:}

Barbadin (3-amino-5-(4-benzylphenyl)-3H,4H-thieno[2,3-d]pyrimidin-4-one) (Cat No. B118250), Arginine Vasopressin acetic acid salt (AVP) (Cat No. V991535) and Wortmannin (Cat No. W499400), were purchased from Toronto Research Chemicals, Toronto, Ontario, Canada). Trichostatin A (TSA) and dimethyl sulfoxide (DMSO) were from Sigma Chemicals, USA. Earle's balanced salt solution (EBSS) and other cell culture reagents (DMEM $4.5 \mathrm{~g} / \mathrm{L}$ glucose with $\mathrm{L}$ glutamine, penicillin/streptomycin, fetal bovine serum (FBS) and Trypsin/EDTA) were from Lonza Pharma \& Biotech.

\section{Cell culture and treatment}

MDA MB-231 cells [16] was generously provided by Department of Cancer Biology, $\mathrm{NCl}$, Cairo University. Cells were cultured in Dulbecco's modified Eagle's Minimal Essential Medium (DMEM) supplemented with $10 \%$ heat inactivated FBS, $1 \%$ Penicillin/Streptomycin in a humidified atmosphere of $95 \%$ air and $5 \% \mathrm{CO}_{2}$ at $37^{\circ} \mathrm{C}$. Initially, cells were seeded with a low cell density then subcultured with particular densities in $100 \mathrm{~mm}, 6$ wells, or 96 wells plates according to the experimental settings.

\section{Cell treatments}

Autophagy was induced by glucose oxygen deprivation, where cells were starved for 4 hours in EBSS, which does not contain nutrients nor growth factors, at $37^{\circ} \mathrm{C}$. To inhibit autophagy, $100 \mathrm{nM}$ of the $\mathrm{PI3K} / \mathrm{mTOR}$ inhibitor (Wortmannin) was included in the culture media for $24 \mathrm{~h}$. Blocking the interaction between $\beta$-Arr1 and AP2 adaptin protein, cells were treated with $100 \mu \mathrm{M}$ Barbadin for 30 min then 
stimulated with AVP for extra 45 min. Inhibition of histondeacetylases (HDACs) was performed by incubating cells in media containing $0.25 \mu \mathrm{M}$ TSA dissolved in DMSO for $24 \mathrm{~h}$.

\section{Autophagy and Apoptosis assessments}

LC3 II was determined by fluorescent antibody labeling of the microtubule associated protein using Rabbit anti-Homo sapiens (Human) MAP1LC3B Polyclonal antibody (MAP1LC3B Antibody, FITC conjugated), (CUSABIO, USA). Apoptosis assay was performed using Annexin V-FITC kit (Miltenyi Biotech, Auburn, CA, USA) following the manufacturer's instructions. Briefly, subconfluent treated cells were detached from the plates and centrifuged at $1000 \mathrm{rpm}$ for $5 \mathrm{~min}$. Cell pellet was resuspended in $1 \mathrm{ml}$ PBS and then incubated with $0.25 \mu \mathrm{g} / \mathrm{ml}$ Annxin $\mathrm{V}$ in $1 \mathrm{X}$ binding buffer for $15 \mathrm{~min}$, followed by two washes with Wash Buffer. Cells were resuspended again in binding buffer containing $0.5 \mu \mathrm{g} / \mathrm{ml}$ Propidium lodide (PI) then subjected to flow cytometer (BC Novus). The data was recovered and analyzed by Kaluza software.

\section{Cell cycle analysis}

Cells were treated as previously outlined. After treatment periods adherent cells were collected and washed twice with PBS. Cells were permeablized with $70 \%$ ethanol with PBS (v/v) and stored at $4{ }^{\circ} \mathrm{C}$ for at least $2 \mathrm{~h}$. After incubation, cells were washed with PBS and stained with a solution of PBS containing $\mathrm{PI}(50 \mu \mathrm{g} / \mathrm{ml})$, Triton X-100 and RNase A for $30 \mathrm{~min}$ at room temperature in a dark place. Cells suspension was filtered then analyzed on Accuri C6 flow cytometer (Becton Dickinson, Sunnyvale, CA, USA).

Expression of $\mathrm{P} 62$ and $\beta$-arrestin 1

The expression of genes ( $\beta$-Arr1 and P62) was assessed at mRNA levels using Qiagen Rotor-Gene Q PCR Cycler 5 Plex. Total RNA was recovered using GeneJET RNA purification kit, (ThermoFisher Scientific,

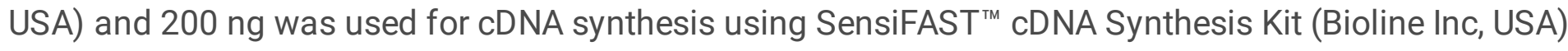
following the manufacturer's protocol. For quantitation, $50 \mathrm{ng} / \mu \mathrm{l}(2 \mu \mathrm{l})$ of cDNA was used as a template in cycling reactions $(20 \mu \mathrm{l})$ containing $50 \mathrm{nmol} / \mu \mathrm{l}(2 \mu \mathrm{l})$ of gene-specific primers (Table 1). The reaction mix included 10 QIAGEN SYBR green, raised to $20 \mu \mathrm{l}$ with water then subjected to a thermal cycling program consisted of a single step of denaturation followed by 45 cycles (each consisted of single denaturation at $94{ }^{\circ} \mathrm{C}$ for $5 \mathrm{sec}$, annealing at $62{ }^{\circ} \mathrm{C}, 55$ and 62 and $65^{\circ} \mathrm{C}$ (for P62, and $\beta$-Arr 1 , and GAPDH, respectively) and an extension step at $72{ }^{\circ} \mathrm{C}$ for $20 \mathrm{sec}$. Reactions were terminated with a single step at $99^{\circ} \mathrm{C}$ to produce a melt curve. In parallel, the expression of GAPDH was used as an internal control to determine the fold expression changes of the targeted genes. The critical threshold $(\mathrm{Ct})$ of target genes was normalized with quantities (Ct) of GAPDH by using the $2^{-\Delta \Delta C t}$. 
Table 1

Sequence of primers used in the expression analysis of epigenetic and drug metabolism related genes.

\begin{tabular}{|ll|}
\hline \multicolumn{2}{|l|}{ Primer Sequence } \\
\hline Beclin1 & $\begin{array}{l}\text { For: 5'-AGCTGCCGTTATACTGTTCTG-3' } \\
\text { Rev: 5'ACTGCCTCCTGTGTCTTCAATCTT3' }\end{array}$ \\
\hline P62 & $\begin{array}{l}\text { For: 5'TTCGCAAGGACCTGTTTGT-3', } \\
\text { Rev: 5'-GGAGGGATCTCAAAGGTGAAAG - 3' }\end{array}$ \\
\hline GAPDH & For: GGCGCTGAGTACGTCGTGGAGT \\
\hline For: Forward (sense) \\
\hline Rev: Reverse (antisense) \\
\hline
\end{tabular}

\section{Statistical data analysis}

SPSS13.0 software package was used to analyze the data. All cell culture work was performed in triplicates and the average values were determined. Apoptosis was measured and displayed in histograms and as a percent of the control and represented as the mean of 3 runs \pm SD (standard deviation). $P$ values less than 0.5 were considered to indicate significant differences. ClustVis was used to cluster the effect TSA versus Barbadin and Wortmannin.

\section{Results}

We first determined the level of the autophagy marker when cells were transiently starved by the autophagy inducing media (EBSS), treated with the autophagy inhibitor (Wort) or both. Autophagy was assessed by fluorescent antibody labeling of the microtubule associated protein, LC3 II, and compared to its basal level of the untreated cells, grown normal media. Also, the mRNA expression of P62 was determined. Then we compared these conditions with the corresponding effect observed in agonist (AVP) activated cells treated with Barbadin as $\beta$-Arr inhibitor. Cells starved in EBSS for $4 \mathrm{~h}$ demonstrated higher expression of LC3II protein $(66.7 \pm 2.2)$ compared to the basal level $(30.03 \pm 0.95)$ seen in cells grown in normal nutrients and growth factors $(\mathrm{P}<0.001)$. The PI3K inhibitor (Wort), in contrast, significantly reduced LC3II protein to $13.2 \pm 0.55(P<0.05)$. In cells transiently grown in EBSS followed by Wort, the LC3II was $54.2 \pm 2.61$ indicating the irreversible effect of starvation induced autophagy even when PI3K was inhibited (Fig. 1). To inhibit the interaction between $\beta$-Arr1 with the adaptor protein AP2, Barbadin was used in treatment of agonists (AVP) stimulated cells, where it increased LC3II to $51.27 \pm 0.11$ compared to Barbadin untreated and AVP unsensitised cells $(P<0.001)$. Barbadin/AVP treatment, 
however, did not induce additive autophagic effect in pre-starved cells (LC3II: $55.8 \pm 2.25, \mathrm{P}>0.05$ ). Moreover, no synergistic autophagic effect was observed in cells treated with bioth Barbadin and Wort. (LC3II: $49.7 \pm 1.3$ ) (Fig. 1).

We next examined whether these autophagic effects were associated with apoptosis. Cells which were starved with EBSS, treated with Wort or Barbadin/AVP exhibited morphological characteristics of apoptosis including shrinkage, rounding and detachment (Fig. 2A). The percent of cell viability was reduced when cells grown in EBSS, cells treated with Wort, Barbadin/AVP or both (Wort + Barbadin/AVP) to $71.3 \%, 75.4 \%, 69.1 \%$ and $67.1 \%$, respectively. Meanwhile, apoptosis was developed in $28 \%, 22 \%, 29.9 \%$ and $32.7 \%$, of cells respectively (Fig. 2B\&C). As in apoptotic cells, the low molecular weight internucleosomal DNA fragments are extracted during cell staining in aqueous solution, so apoptotic cells are identified on DNA content frequency histograms as sub-G1 fraction as a hallmark of apoptosis. As Fig. 3 shows, the sub-G1 fractions developed in cells starved with EBSS, treated with Wort or Barbadin/AVP were 39.5\%, $27.8 \%$ and $31.5 \%$, respectively. Also, the percent of cells arrested in G0/G1 phase was $54.2 \%, 77.6 \%$ and $79.4 \%$, respectively. All the changes observed in sub-G1 and arrested cells were significant compared to the normally grown untreated cells.

The mRNA levels of some relevant genes were investigated using reverse transcription PCR. Downregulation was the hallmark of $\beta$-Arr1 and none of the drugs were able to modulate its expression profile. P62, in contrast, which is used as autophagy marker at its protein level, demonstrated varying mRNA expression levels, where it was upregulated (about 2 fold increase) in cells grown in EBSS, cells treated with Wort or in agonist activated cells treated with Barbadin. Also, combined treatment with Wort and Barb/AVP exerted a synergistic effect in P62 regulation and Beclin 1 (Fig. 4). As histone deacetylase 6 (HDAC6) is involved in $\beta$-Arr mediated tubulin acetylation/deacetylation that affects cell migration, we thought to monitor the corresponding autophagic/apoptotic potential of HDAC inhibition compared to that of Barbadin. Cells treated with TSA (HDACs inhibitor) showed apoptotic cell morphological appearance, developed autophagy (LC3 II: $48.2 \pm 1.5$ ), apoptosis ( $27.8 \%$ of cells) and arrested $63.7 \%$ of cells in G0/G1. Moreover, TSA did not affect the expression of $\beta$-Arr1 but rather downregulated P62 compared to Barbadin (Fig. 5).

\section{Discussion}

In this work, Barbadin was used to functionally hinder the interaction between $\beta$-Arr1 and $\beta 2$-adaptin subunit of the clathrin adaptin protein-2 (AP2). This does not interfere with the formation of the membrane receptor/ $\beta$-Arr complex [17]. The hormonal agonist (AVP) we used, is known to ligand with $\mathrm{V} 2 \mathrm{R}$ receptor and stimulates ERK1/2 pathway (independently of heterotrimeric $\mathrm{G}$ protein signaling). Also, ERK1/2 stimulation involves $\beta$-Arr [18]. Thus, it was anticipated that treatment of cells with Barbadin may block V2R-stimulated ERK1/2 activation and prohibits the intracellular accumulation of cAMP and downstream signaling. MDA MB-231 cells are highly metastatic TNBC cells [19], expresses V2R receptor [20] and non-visual arrestins ( $\beta$-arr 1\&2). We have employed this cellular, in vitro, model to reveal the direct 
impact of $\beta$-Arr inhibition on cellular events including autophagy, apoptosis and cell cycle progression and the subsequent anticancer potential of Barbadin.

Growing cells in starvation conditions (in EBSS) is well established protocol to induce autophagy [21]. Limited starvation ( $4 \mathrm{~h}$ ) was sufficient to induce autophagy, as indicated by 2 -fold increase in the microtubule-associated protein light chain 3 (LC3II) compared to its basal level in cells grown in nutrients rich condition. Starvation-induced autophagy was associated with apoptosis in $28 \%$ of cells dually stained with AV/PI. The displacement of Bcl-2 from Beclin-1 and Bax, may be the driving force that triggered both autophagy and apoptosis [22]. In similar work, starved MDA MB-231 cells developed autophagy through the AMBRA1/mTOR pathway leading to an increase of LC3II, increase of autophagosomes but decrease of p62 protein [23]. The PI3K inhibitor (Wort) is commonly used as an autophagy inhibitor, based on its inhibitory effect on class III PI3K activity, which is known to be essential for induction of autophagy. The LC3II in Wort treated cells was significantly reduced. Unexpectedly, both cytotoxic mechanisms were associated with mild increase in the expression of P62 mRNA. Although P62 protein was not assessed in this work, the relative overexpression of its coding gene may help to replenish selective degradation of P62 protein during the initial stages of autophagy [24]. This may occur during the first few hours of starvation and before the turnover of P62 protein. In this process, P62 protein acts as an intracellular receptor for ubiquitinated proteins, where the P62-ubiquitinated complex is merged with LC3II, and the new complex is sequestered in the autophagosomes [25]. Also, the increased P62 mRNA, we observed, may be attributed to the increased response to the proteasome inhibitor (PSI) or prostate-derived Ets factor (PDEF) [26].

An altered scenario was observed when cells were treated with Wort, where autophagy was inhibited, as indicated by the significant decrease of LC3 II compared to its basal level. Additionally, Wort developed apoptosis in $22 \%$ of cells. Wort-mediated autophagy inhibition may occur through inhibiting the conversion of PIP2 into PIP3 and phosphorylation of AKT leading to the inhibition of PI3k/AKT pathway [27]. Cells transiently exposed to harsh conditions followed by Wort have maintained their high LC3II protein and developed more apoptosis (31\% of cells) indicating the irreversibility of starvation-induced autophagy. In similar studies, concomitant exposure of mouse embryonic fibroblasts (MEF) cells to Wort or 3-methyladenine during starvation, led to the suppression of starvation-induced autophagy [28]. Cell cycle analysis confirmed the association between autophagy and apoptosis, where about $39 \%$ of cells were trapped in Sub-G1 phase, and more cells (54\%) were arrested in G0/G1 phase, the observation previously reported in both TNBC (MDA MB-231) [27] and the less aggressive luminal A cells (MCF-7) [29].

Nonvisual $\beta$-Arrs, on the other hand, play a key role in mediating cellular cytoprotective events through the activation of GPCRs [30]. They participate in cancer invasion and metastasis [9]. Herein, Barbadin mediated $\beta$-Arr inhibition, in cells grown in normal condition, was associated with autophagy and developed apoptosis as similar as starved cells (EBSS-incubation). The inhibition of $\beta$-Arr/AP2 interaction may provide more chance for $\beta$-Arr to act as a caspase substrate, where its cleaved fragments participate in the core mechanism of apoptosis and assist other product of caspase activity in releasing the mitochondrial Cytochrmome [31]. Also, Barbadin autophagic/apoptotic effect was associated in G0/G1 
arrest. These observations are supported by some previous reports in which $\beta$-Arr 1 depletion, markedly induced neuronal apoptosis/necrosis in vivo and in vitro [32]. Also, siRNA-mediated silencing of $\beta$-Arr1 \&2 reduced ERK1/2 activation and MDA MB-231 cells metastasis [12]. In addition, $\beta$-Arr2-associated type III transforming growth factor- $\beta$ receptor negatively mediated the migration and invasion of MDA-MB-231 breast cancer cells via NF-KB signaling [33]. Our observations indicated that Barbadin did not exert additional autophagic effect after cells were desensitized with EBSS, most probably due to the internalization of their GPCRs. This was evidenced by the insignificant differences in LC3II protein, P62 mRNA and apoptosis in Barbadin treated cells with or without starvation. Moreover, the autophagic role of Barbadin did not involve PI3K signaling, where cells cotreated with Barbadin and Wort did not show significant changes in the magnitude of autophagy. More importantly, the data predicts the dependence of Barbadin-induced apoptosis on autophagy, where cotreatment of cells with Wort and Barbadin resulted in higher proportion of cells in Sub-G1 peak (31.9\%) and higher percent of apoptotic cells (32.7\%) (Fig 2) The intervening role of P62 seems to be cell type and/or autophagy phase dependent. P62, it is multifunction and involved in other pathways including the UPS [34]. The increased synthesis of P62 could be triggered through the effect of some transcription factors, such as Nrf2, where P62 is phosphorylated to participate in autophagy flux [35]. This hypothesis is supported by the decreased expression of P62 in Wort treated cells. Other expression data revealed low expression of $\beta$-Arr 1 mRNA is consistent with clinical studies in which $\beta$-Arr 1 was inversely correlated with the histological grade of breast cancer and positively associated with TNBC patient survival, suggestive of a tumor-suppressive function of $\beta$-Arrs1 in breast cancer patients [13]. Silencing of $\beta$-Arr1 increased the migration potential of MDA MB-468 and MDA MB-231 cells [36]. The autophagy/apoptosis effect of Barbadin is exterted through the hindrance of the covalent interaction between $\beta$-Arr and AP2 $\beta$-adaptin subunit, where Barbadin is superimposited with the $\beta$-Arr 1 C-terminus peptide where Phe-388, Phe-391 and Arg-395 are the three key residues for $\beta$-Arr binding [17]. This may exclude possible direct effect of Barbadin on $\beta$-Arr1 expression.

In parallel, histone deacetylases (HDACs) 1, 6 and 8 are deeply involved in invasion of breast cancer [37]. HDAC6, in particular, plays a critical role in the ubiquitinated aggregate formation and autophagosomelysosome fusion. Although this role is mediated by P62, other studies revealed the involvement of HDAC6 in $\beta$-Arr mediated tubulin acetylation/deacetylation that affects cell migration. Thus, we thought to monitor the autophagic/apoptotic potential of HDAC inhibition compared that induced by $\beta$-Arr inhibitor. Treatment of cells with HDACl (TSA), resulted in regression of cells viability, induction of autophagy, massive necrosis and cell cycle arrest in G0/G1 phase. These observations are largely consistent with previous reports that nominated TSA as anticancer drug through the induction of both autophagy [38] and apoptosis [39]. These findings, however, predict that TSA may adopt different anticancer mechanism as indicated by its necrotic effect and the downregulation of P62 mRNA. Correlation based clustering revealed that TSA effects did not tightly cluster with Barb/AVP or Wort effects (Fig 5). This added to its well reported epigenetic mechanism in acetylating genes and transcription factors.

\section{Conclusion}


Although the mechanisms underlying these events need ore exploration, the outcomes revealed the potential and beneficial therapeutic role of $\beta$-Arr inhibition in breast cancer management. The study suggests autophagic and apoptotic effects of $\beta$-arrestin inhibition by Barbadin in a dependent manner and the association of both mechanisms with cell cycle arrest in G0/G1 phase. This approach promotes selective targeting the intracellular endocytic proteins as therapeutic targets in advanced stages of breast cancer.

\section{Declarations}

\section{Disclosure statement}

The authors report no conflicts of interest.

\section{Authors' contributions:}

Conceptualization: $\mathrm{MH}$ and TD; Methodology and investigations: MA, MK, TD and MH; Editing the original draft and revision: $\mathrm{MH}, \mathrm{MK}$ and TD; Project administration, $\mathrm{MH}$; Funding acquisition, $\mathrm{MH}, \mathrm{TD}, \mathrm{MK}$.

\section{Acknowledgment}

Authors would like to express their gratitude towards Science and Technology Development Fund (STDF), for providing the financial supported to this work (grant number 34850).

\section{References}

1. Tsujimoto Y, Shimizu S. Another way to die: autophagic programmed cell death. Cell Death Differentiation. 2005;12(2):1528-34.

2. Gewirtz DA. The four faces of autophagy: implications for cancer therapy. Cancer research. 2014;74(3):647-51.

3. Eisenberg-Lerner A, Bialik S, Simon H-U, Kimchi A. Life and death partners: apoptosis, autophagy and the cross-talk between them. Cell Death Differentiation. 2009;16(7):966-75.

4. Gurevich VV, Gurevich EV. The structural basis of arrestin-mediated regulation of G-protein-coupled receptors. Pharmacol Ther. 2006;110(3):465-502.

5. Kang Y, Zhou XE, Gao X, He Y, Liu W, Ishchenko A, Barty A, White TA, Yefanov O, Han GW. Crystal structure of rhodopsin bound to arrestin by femtosecond X-ray laser. Nature. 2015;523(7562):561-7.

6. Goodman OB, Krupnick JG, Santini F, Gurevich VV, Penn RB, Gagnon AW, Keen JH, Benovic JL. $\beta$ Arrestin acts as a clathrin adaptor in endocytosis of the $\beta$ 2-adrenergic receptor. nature. 1996;383(6599):447-50.

7. Luttrell L, Ferguson S, Daaka Y, Miller W, Maudsley S, Della Rocca G, Lin F-T, Kawakatsu H, Owada K, Luttrell D. $\beta$-Arrestin-dependent formation of $\beta 2$ adrenergic receptor-Src protein kinase complexes. Science. 1999;283(5402):655-61. 
8. Jean-Charles PY, Kaur S, Shenoy SK. GPCR signaling via $\beta$-arrestin-dependent mechanisms. J Cardiovasc Pharmacol. 2017;70(3):142.

9. Song Q, Ji Q, Li Q. The role and mechanism of $\beta$-arrestins in cancer invasion and metastasis. Int J Mol Med. 2018;41(2):631-9.

10. Shukla AK, Dwivedi-Agnihotri H Structure and function of $\beta$-arrestins, their emerging role in breast cancer, and potential opportunities for therapeutic manipulation. Advances in Cancer Research. Vol 145: Elsevier; 2020:139-156.

11. Wahba HA, El-Hadaad HA. Current approaches in treatment of triple-negative breast cancer. Cancer biology medicine. 2015;12(2):106.

12. Ge L, Shenoy SK, Lefkowitz RJ, DeFea K. Constitutive protease-activated receptor-2-mediated migration of MDA MB-231 breast cancer cells requires both $\beta$-arrestin-1 and-2. J Biol Chem. 2004;279(53):55419-24.

13. Luttrell L, Ferguson S, Daaka Y, Miller W, Maudsley S, Della Rocca G, Lin F-T, Kawakatsu H, Owada K, Luttrell D. $\beta$-Arrestin-dependent formation of $\beta 2$ adrenergic receptor-Src protein kinase complexes. Science. 1999;283(5402):655-61.

14. Feigin ME, Xue B, Hammell MC, Muthuswamy SK. G-protein-coupled receptor GPR161 is overexpressed in breast cancer and is a promoter of cell proliferation and invasion. Proceedings of the National Academy of Sciences. 2014;111(11):4191-4196.

15. Jing $X$, Zhang H, Hu J, Su P, Zhang W, Jia M, Cheng H, Li W, Zhou G. $\beta$-arrestin 2 is associated with multidrug resistance in breast cancer cells through regulating MDR1 gene expression. Int $\mathrm{J}$ Clin Exp Pathol. 2015;8(2):1354.

16. Cailleau R, Young R, Olive M, Reeves W Jr. Breast tumor cell lines from pleural effusions. J Natl Cancer Inst. 1974;53(3):661-74.

17. Beautrait A, Paradis JS, Zimmerman B, Giubilaro J, Nikolajev L, Armando S, Kobayashi H, Yamani L, Namkung $Y$, Heydenreich FM. A new inhibitor of the $\beta$-arrestin/AP2 endocytic complex reveals interplay between GPCR internalization and signalling. Nature communications. 2017;8(1):1-16.

18. Charest PG, Oligny-Longpré G, Bonin H, Azzi M, Bouvier M. The V2 vasopressin receptor stimulates ERK1/2 activity independently of heterotrimeric $G$ protein signalling. Cellular signalling. 2007;19(1):32-41.

19. Liu WJ, Ye L, Huang WF, Guo LJ, Xu ZG, Wu HL, Yang C, Liu HF. p62 links the autophagy pathway and the ubiqutin-proteasome system upon ubiquitinated protein degradation. Cell Mol Biol Lett. 2016;21(1):29.

20. Garona J, Pifano M, Orlando UD, PAsTRIAN MB, lannucci NB, Ortega HH, PODEsTA EJ, Gomez DE, Ripoll GV, ALONsO DF. The novel desmopressin analogue [V4Q5] dDAVP inhibits angiogenesis, tumour growth and metastases in vasopressin type 2 receptor-expressing breast cancer models. Int $\mathrm{J}$ Oncol. 2015;46(6):2335-45.

21. Cui J, Lu K, Shi Y, Chen B, Tan S-H, Gong Z, Shen H-M. Integrated and comparative miRNA analysis of starvation-induced autophagy in mouse embryonic fibroblasts. Gene. 2015;571(2):194-204. 
22. Chiu C-F, Chin H-K, Huang W-J, Bai L-Y, Huang H-Y, Weng J-R. Induction of Apoptosis and Autophagy in Breast Cancer Cells by a Novel HDAC8 Inhibitor. Biomolecules. 2019;9(12):824.

23. Zhu W, Qu H, Xu K, Jia B, Li H, Du Y, Liu G, Wei HJ, Zhao HY. Differences in the starvation-induced autophagy response in MDA-MB-231 and MCF-7 breast cancer cells. Anim Cells Syst (Seoul). 2017;21(3):190-8.

24. Ichimura $Y$, Komatsu M. Selective degradation of p62 by autophagy. Paper presented at: Seminars in immunopathology, 2010;32(4):431-6.

25. Komatsu M, Ichimura Y. Physiological significance of selective degradation of p62 by autophagy. FEBS Lett. 2010;584(7):1374-8.

26. Thompson HGR, Harris JW, Wold BJ, Lin F, Brody JP. p62 overexpression in breast tumors and regulation by prostate-derived Ets factor in breast cancer cells. Oncogene. 2003;22(15):2322-33.

27. Li J, Li F, Wang H, Wang X, Jiang Y, Li D. Wortmannin reduces metastasis and angiogenesis of human breast cancer cells via nuclear factor-кB-dependent matrix metalloproteinase-9 and interleukin-8 pathways. J Int Med Res. 2012;40(3):867-76.

28. Wu Y-T, Tan H-L, Shui G, Bauvy C, Huang Q, Wenk MR, Ong C-N, Codogno P, Shen H-M. Dual role of 3methyladenine in modulation of autophagy via different temporal patterns of inhibition on class I and III phosphoinositide 3-kinase. J Biol Chem. 2010;285(14):10850-61.

29. Akter R, Hossain MZ, Kleve MG, Gealt MA. Wortmannin induces MCF-7 breast cancer cell death via the apoptotic pathway, involving chromatin condensation, generation of reactive oxygen species, and membrane blebbing. Breast Cancer: Targets Therapy. 2012;4:103.

30. Ahn S, Kim J, Hara MR, Ren X-R, Lefkowitz RJ. $\beta$-Arrestin-2 mediates anti-apoptotic signaling through regulation of BAD phosphorylation. J Biol Chem. 2009;284(13):8855-65.

31. Kook S, Gurevich VV, Gurevich EV. Arrestins in apoptosis. Arrestins-Pharmacology: Springer; 2014. pp. 309-39.

32. Wang P, Xu T-Y, Wei K, Guan Y-F, Wang X, Xu H, Su D-F, Pei G, Miao C-Y. ARRB1/ $\beta$-arrestin-1 mediates neuroprotection through coordination of BECN1-dependent autophagy in cerebral ischemia. Autophagy. 2014;10(9):1535-48.

33. Seo J, Tsakem EL, Breitman M, Gurevich VV. Identification of arrestin-3-specific residues necessary for JNK3 kinase activation. J Biol Chem. 2011;286(32):27894-901.

34. Shin WH, Park JH, Chung KC. The central regulator p62 between ubiquitin proteasome system and autophagy and its role in the mitophagy and Parkinson's disease. BMB Rep. 2020;53(1):56.

35. Liu Y-L, Chou C-K, Kim M, Vasisht R, Kuo Y-A, Ang P, Liu C, Perillo EP, Chen Y-A, Blocher K. Assessing metastatic potential of breast cancer cells based on EGFR dynamics. Scientific reports. 2019;9(1):113.

36. Lundgren K, Tobin NP, Lehn S, Stål O, Rydén L, Jirström K, Landberg G. Stromal expression of $\beta$ arrestin-1 predicts clinical outcome and tamoxifen response in breast cancer. J Mol Diagn. 2011;13(3):340-51. 
37. Park SY, Jun J, Jeong KJ, Heo HJ, Sohn JS, Lee HY, Park CG, Kang J. Histone deacetylases 1, 6 and 8 are critical for invasion in breast cancer. Oncol Rep. 2011;25(6):1677-81.

38. Bai Y, Chen Y, Chen X, Jiang J, Wang X, Wang L, Wang J, Zhang J, Gao L. Trichostatin A activates FOXO1 and induces autophagy in osteosarcoma. Archives of Medical Science: AMS. 2019;15(1):204.

39. Alao JP, Lam EW, Ali S, Buluwela L, Bordogna W, Lockey P, Varshochi R, Stavropoulou AV, Coombes RC, Vigushin DM. Histone deacetylase inhibitor trichostatin A represses estrogen receptor adependent transcription and promotes proteasomal degradation of cyclin D1 in human breast carcinoma cell lines. Clin Cancer Res. 2004;10(23):8094-104.

\section{Figures}

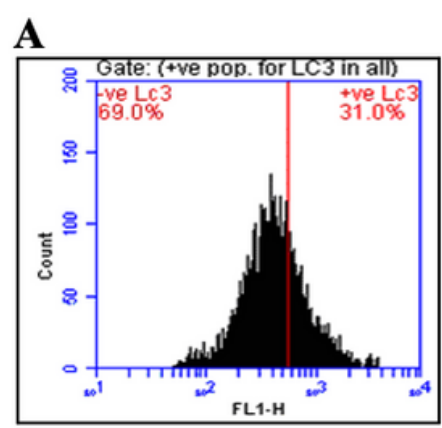

B

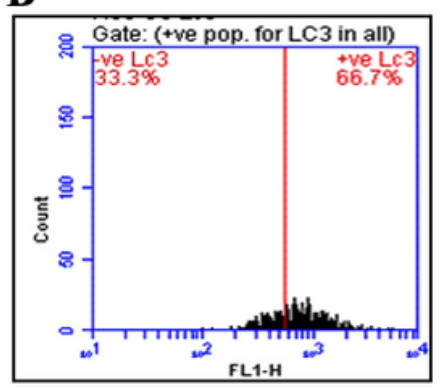

$\mathbf{E}$

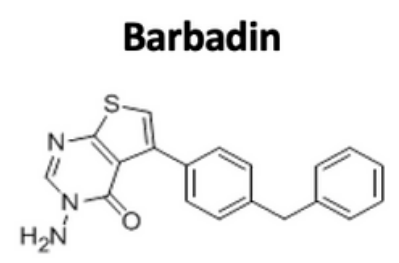

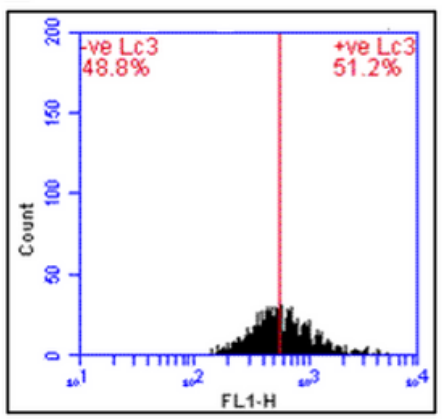

H

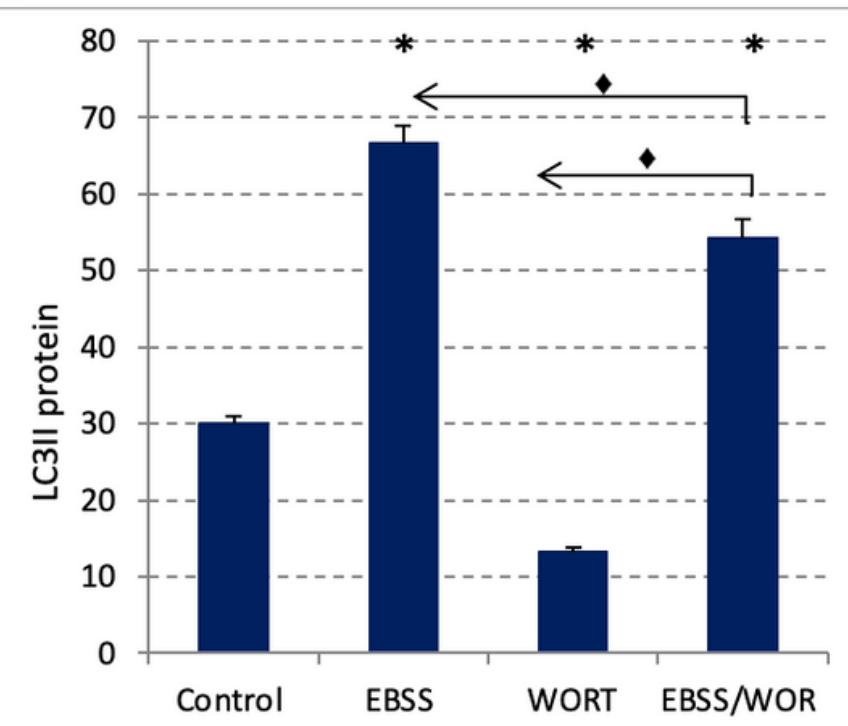

C
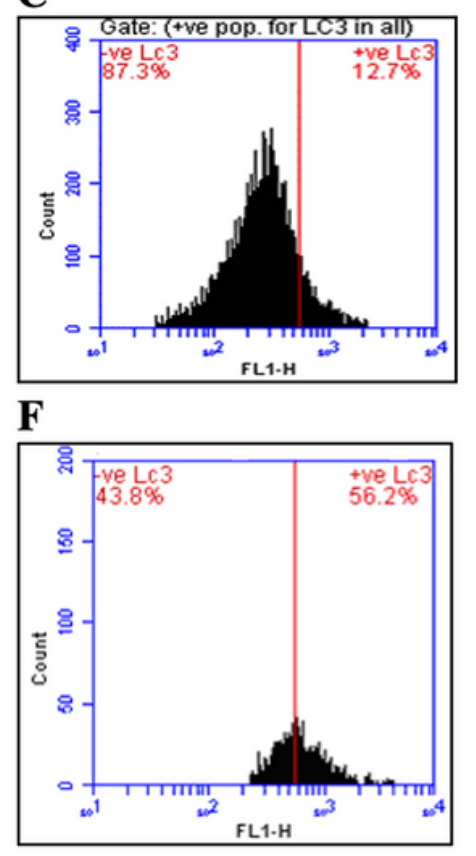

I

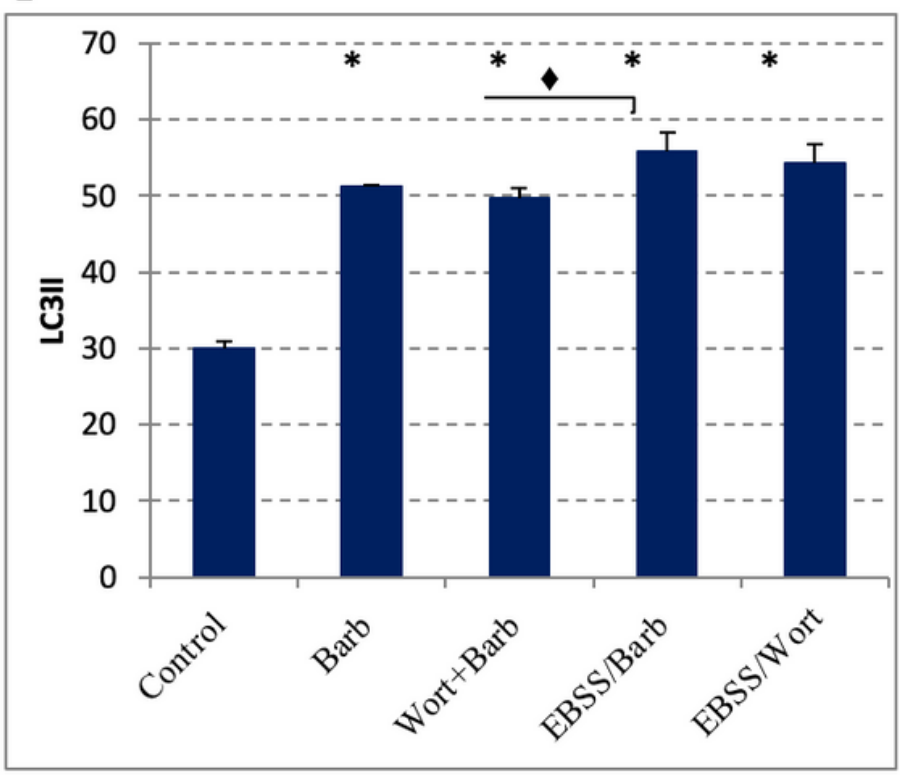

D

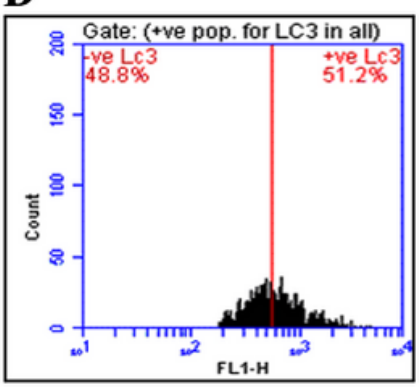

$\mathbf{G}$

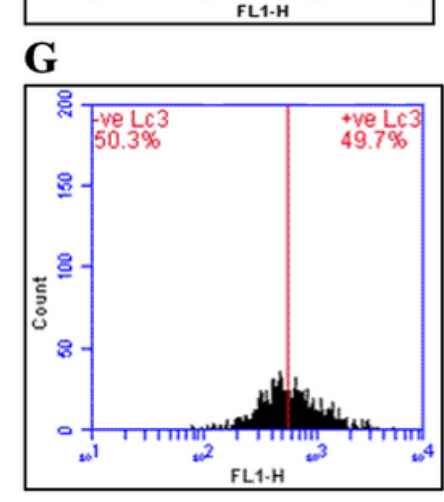




\section{Figure 1}

$\beta$-arrest inhibition induces PI3K-independent autophagy in triple negative breast cancer cells. MDA-MB231 were seeded with an initial cell density 4X104 grown in nutrient rich conditions and left untreated (A), or starved in EBSS (B), treated with Wort (C), starved for $4 \mathrm{~h}$ and then treated with Wort (D), sensitized with AVP then treated with Barbadin (E), sensitized with AVP then treated with Barbadin and Wort $(F)$, or pre-starved with EBSS, sensitized with AVP then treated with Barbadin (G). After treatment periods, cells were collected and the expression of autophagy protein LC3II was determined by flow cytometry. The autophagy was significantly induced by EBSS and inhibited by Wort. Cells pre-starved with EBSS, flowed by Wort treatment, mildly reduced the expression of LC3II but did not restore its basal level. Also, inhibition of the interaction between $\beta$-Arr and AP2 stimulated autophagy, independently of PI3K inhibition (in presence or absence of Wort). Also, Pre-starving cells did not affect the autophaic effect of $\beta$-arre inhibition. Data are presented as mean \pm SD $(H \& l)$. $(*)$ : refers to significant $(P<0.001)$ difference compared to the untreated cells and $(\checkmark)$ refers to significant $(P<001)$ difference between the indicated cells. 
A

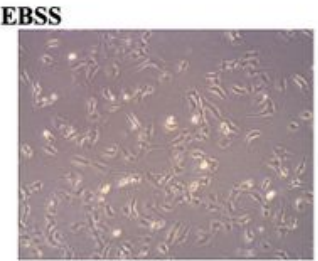

B
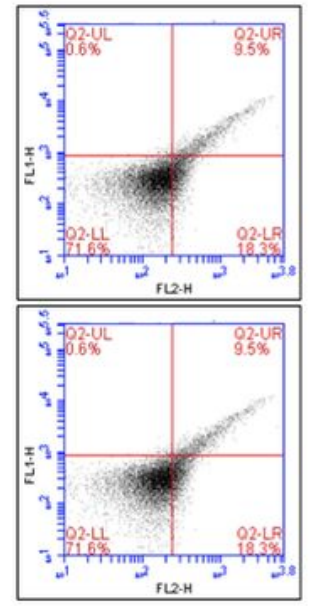

Wort
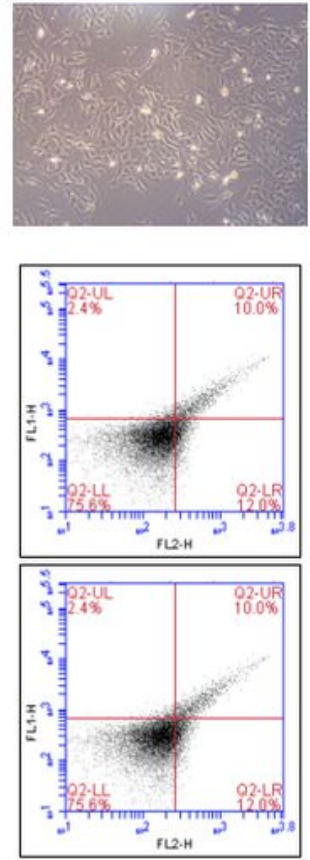

Barbadin
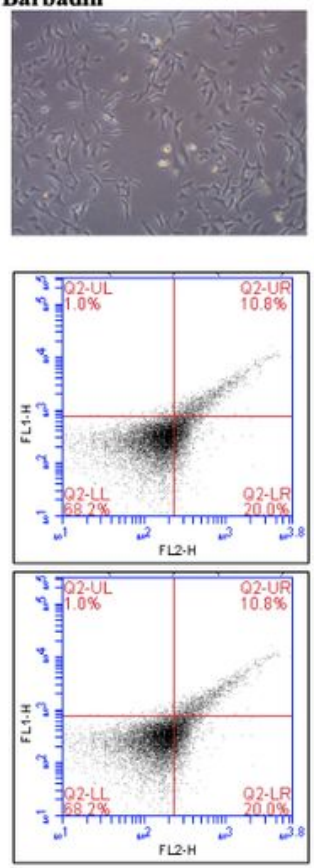

C
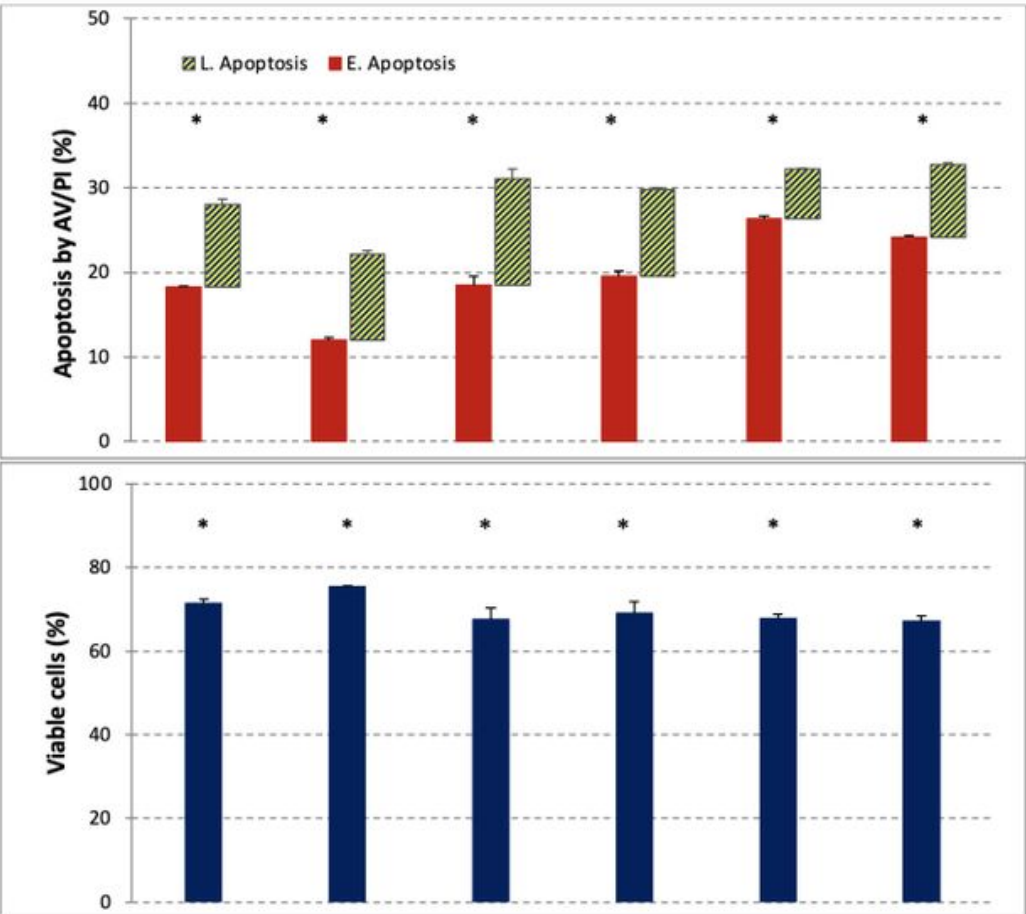

EBSS

Wort

Barb/AVP

\section{Figure 2}

$\beta$-arrestin inhibition induced apoptosis in MDA MB-231 cells in association with autophagy. Phasecontrast photomicrographs taken after starving cells for $4 \mathrm{~h}$, treatment with the autophagy inhibitor (Wort), or $\beta$-arrestin inhibitor (Barbadin/AVP) revealed apoptotic morphological changes including cell shrinkage, rounding and detachment. magnification $\times 400(A)$. Annexin V-FITC and PI staining was used to determine the percentage of viable, dead, early and late apoptotic fractions by flow cytometry (B). Cell 
viability and apoptosis was assessed in following starving cells in EBSS, treatment with Wort, EBSS+Wort, Barbadin/AVP, EBSS+Barbadin/AVP or Barbadin/AVP+Wort. Cell viability significantly decreased in cells incubated in EBSS or treated with Wort, EBSS+Wort, or Barbadin/AVP. Also, treatments resulted in variable degrees of apoptosis. Bar represent the mean $( \pm S D)$ of 3 independent experiments (C). ( $\left.{ }^{\star}\right)$ : significant difference between total apoptosis of the corresponding data versus DMSO treated cells.

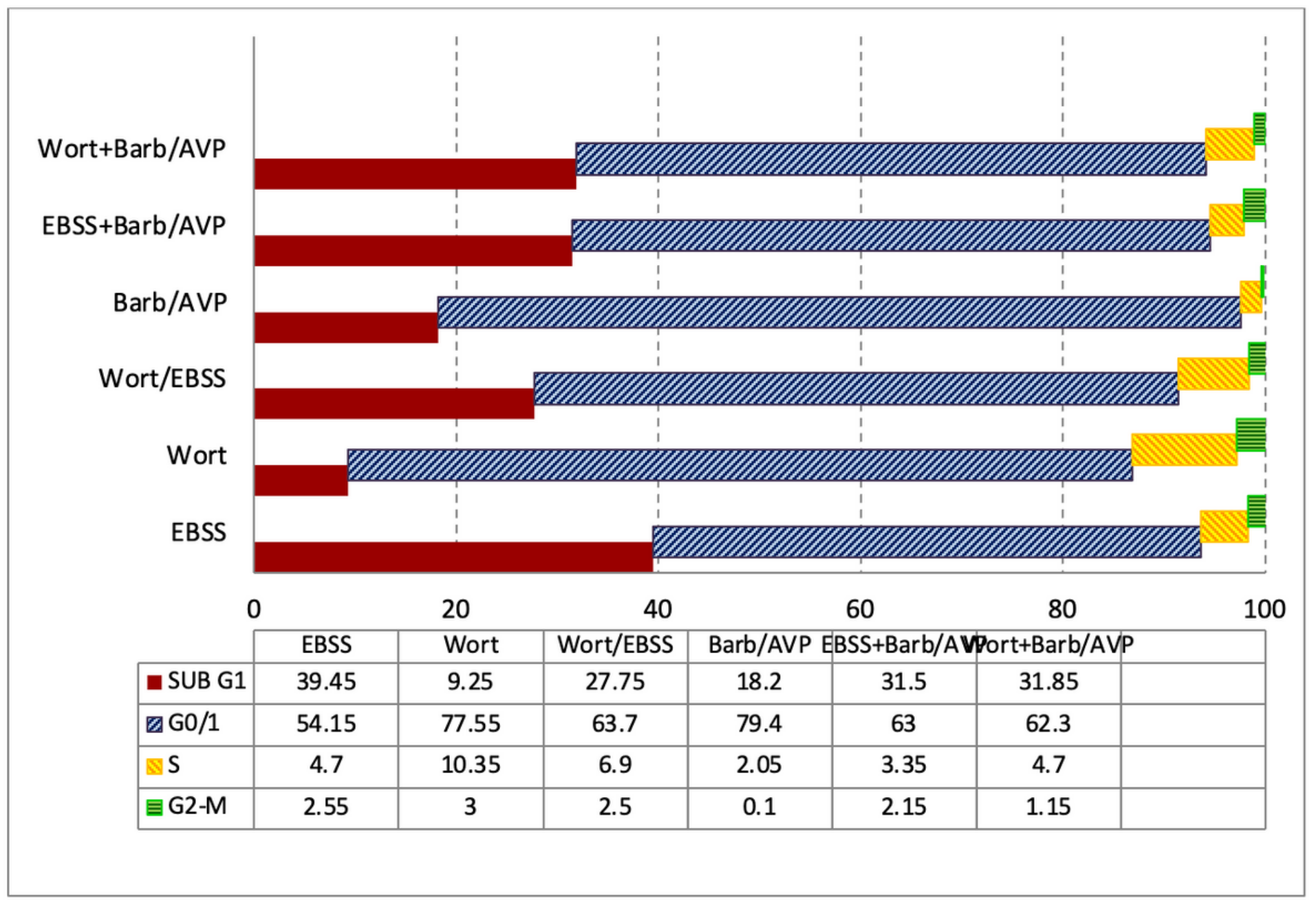

Figure 3

$\beta$-arrestin and autophagy inhibition, independently arrested breast cancer cells in G0/1 phase. MDA MB231 cells were incubated in EBSS, treated with agonist mediated $\beta$-Arr inhibitor (Barbadin/AVP) or the autophagy inhibitor (Wort). At the end of treatment periods, cells were collected and stained with PI and then cell cycle distribution analysis was performed by flow cytometry. Cells were arrested in G0/G1Phase and significant apoptotic fractions of cells were trapped in the sub-G1 phase. 


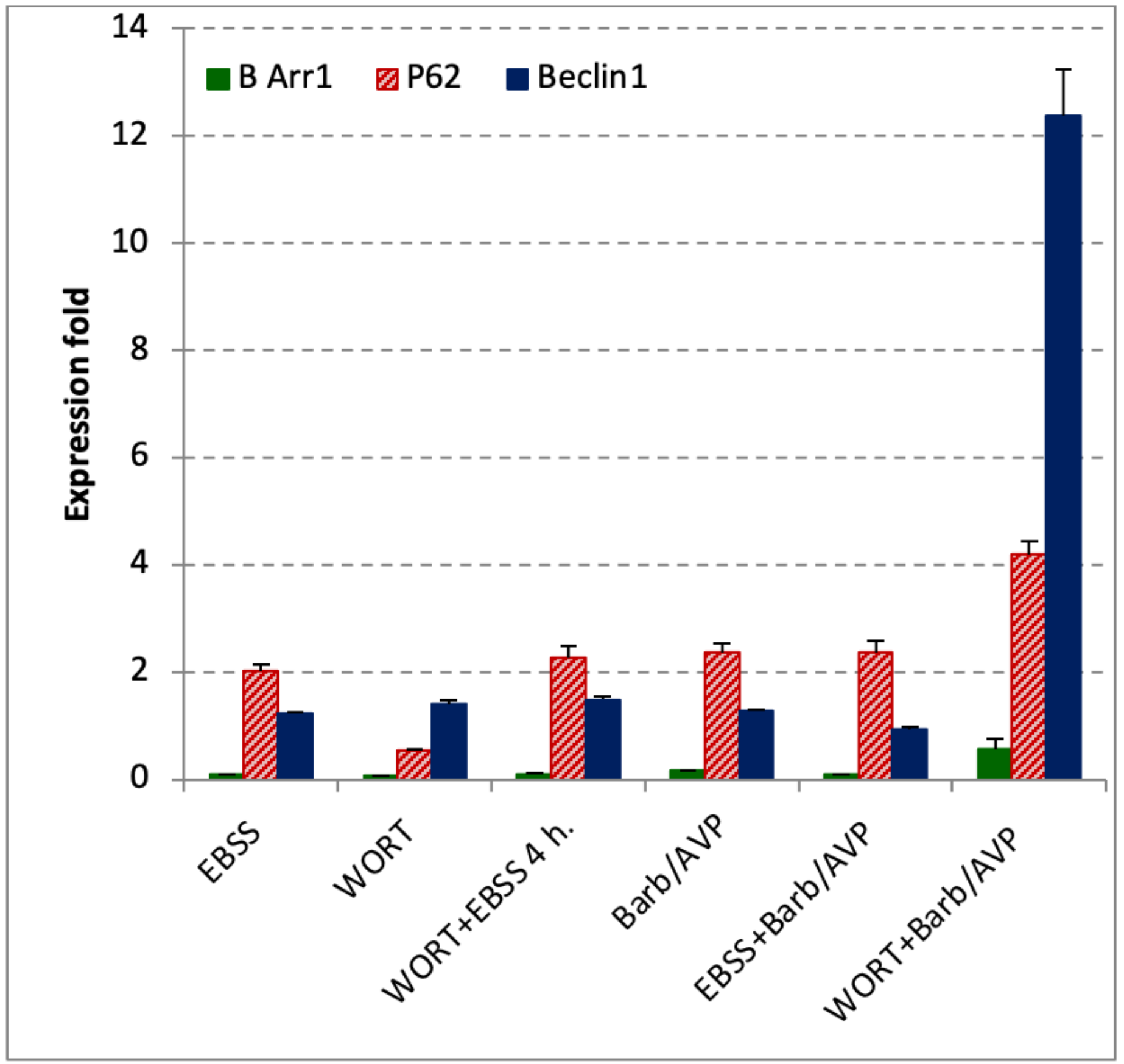

Figure 4

Expression of $\beta$-Arr1, P62 and Beclin 1 in MDA MB-231 cells. Cells were grown in starving media (EBSS), or treated with Barbadin after sensitization with AVP and/or the autophagy inhibitor Wort. After cell collection, mRNA was isolated and reverse transcribed into CDNA, which was used to quantitate the expression level of B Arr1, P62 and Becline. $\beta$ Arre1 was downregulated, whereas P62 upregulated by Barbadin. 


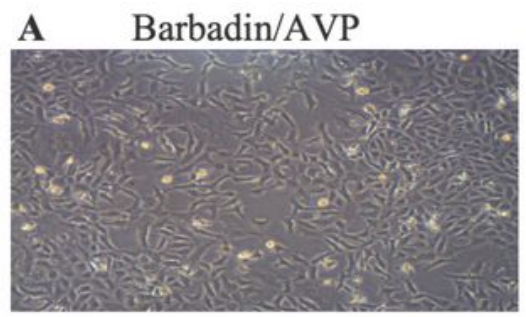

TSA

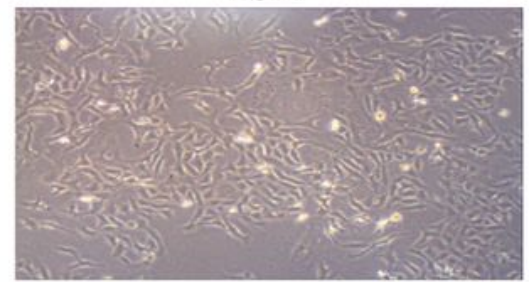

B

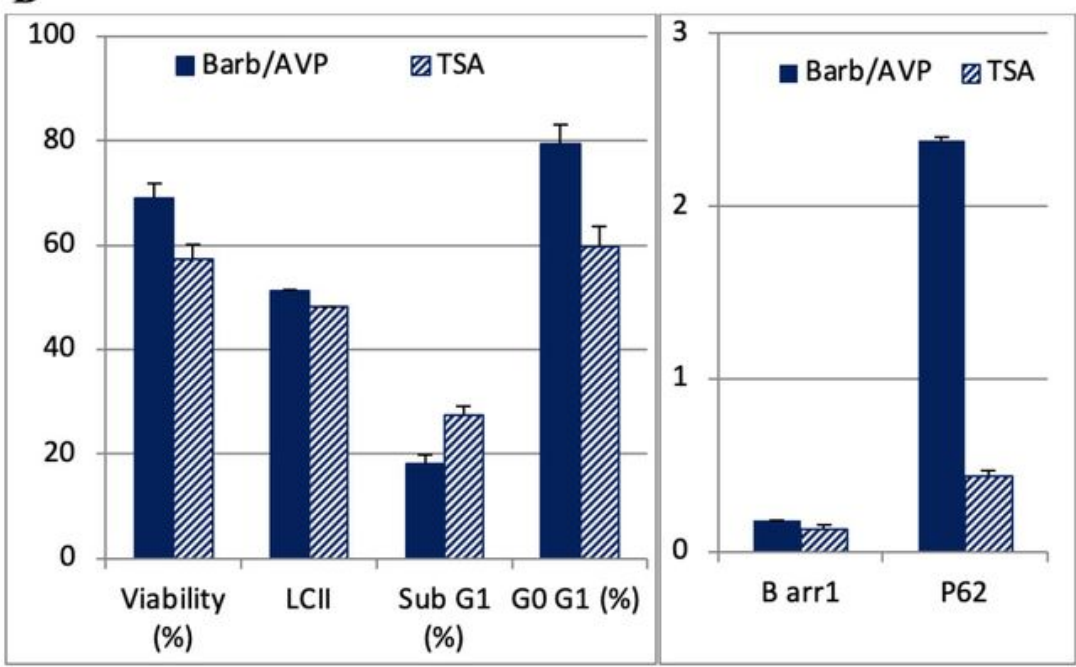

C

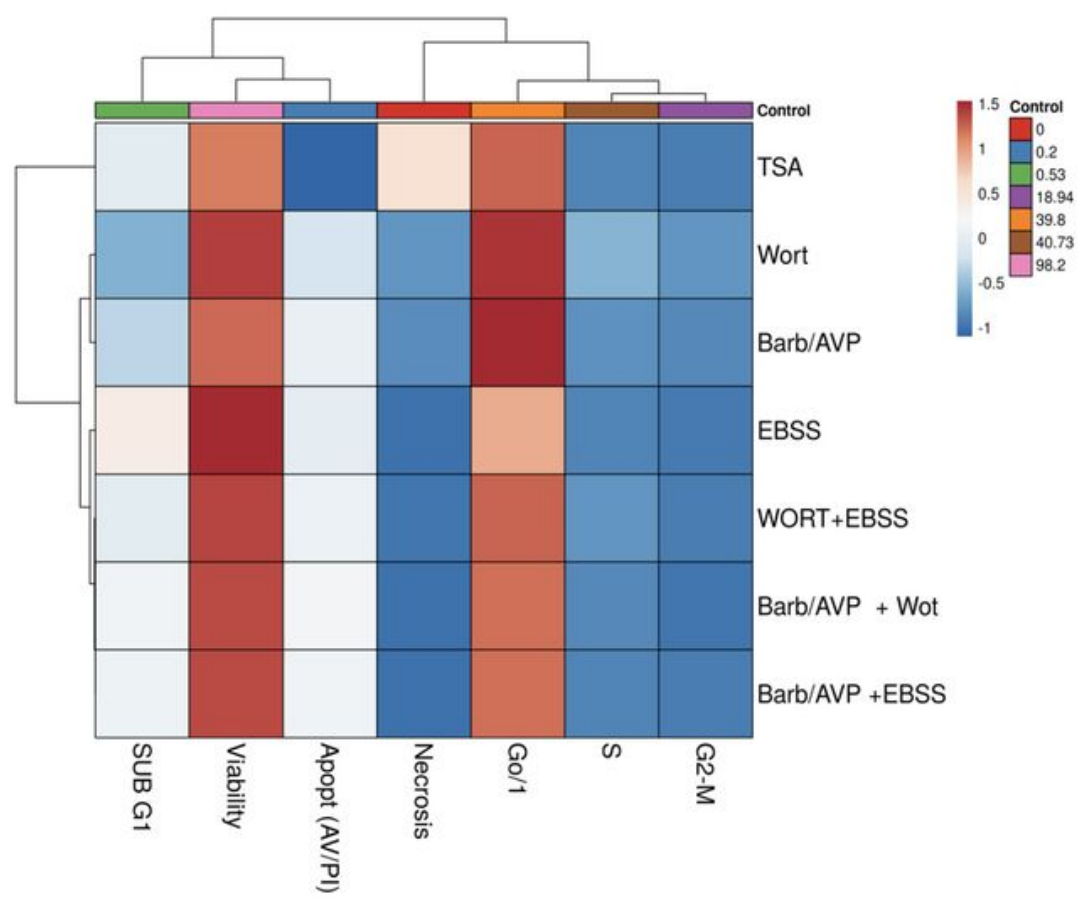

\section{Figure 5}

Comparison the effect of HDACs inhibition versus inhibiting the interaction between $\beta$-arr/AP2 adaptin protein on cells viability, apoptosis (Sub G1 fraction), autophagy-related proteins (LC3II), and the expression levels of $\beta$-Arr1 and P62 mRNA in MDA MB-231 cells. Cells were cultured in presence TSA for $24 \mathrm{~h}$, collected and then used to assess the level of LCll and cell cycle by flow cytometry as explained in Materials and Methods. Also, the mRNA was isolated, reverse transcribed and the levels of $\beta$-arr1 and the 
autophagy marker P62 were determined by reverse transcription PCR. TSA acts as similar as Barbadin in inducing apoptosis cell morphology (panel A), autophagy and cell cycle arrest in G0/G1 phase. TSA, however, downregulated the expression of P62 mRNA (panel B). Panel $C$ represents heatmap of the correlation-based clustering the individual or the combined effect of Barb/AVP, Wort and TSA. Both rows and columns are clustered using correlation distance and average linkage. TSA did not tightly cluster with Barb/AVP or Wort effect indicting its varying anticancer mechanism. 